\title{
La necesidad de coherencia entre la estética y la ética de las organizaciones
}

\section{Coherence Necessity between Organizations Aesthetics and Ethics}

\section{Javier Barraca Mairal*}

\section{Resumen}

Toda organización tiene una dimensión estética, en el sentido de formal, de disposición de su aspecto. Esta ha de manifestarse "congruente" con la dimensión ética o de la responsabilidad. Una organización no puede "aparecer" en sus formas como en realidad no es. Formas y fondo deben ir acompasados en la vida corporativa. De otro modo, además del engaño que puede propiciarse, se produce una falta de armonía y consistencia en cuanto a la "identidad y cultura corporativas". La ausencia de integración y coherencia entre lo mostrado y lo real genera confusión. Ello conduce a la decepción y pérdida de "confianza" en la organización, y al fracaso de sus relaciones. De aquí, la necesidad de progresar - de manera continua- en el cuidado de la convergencia entre los aspectos estéticos y éticos, por parte de cualquier organización y de desarrollar un liderazgo que los integre armoniosamente.

Palabras clave: Coherencia, estética, ética, organizaciones, liderazgo, cultura corporativa.

\section{Abstract}

Every single organization has an aesthetic dimension, in formal sense, its aspect disposition. This is "congruent" with the ethics dimension or responsibility. An organization cannot "show" in its forms, as it is not really. Forms and cruxes must be together in the corporativelife. If not, besides of the possible deception, a lack of harmony and consistency is produced regarding "corporative identity and culture". Integration and coherence absence between the shown aspects and the real ones generate confusion. This conducts to the deception and "confidence" lose in the organization and the failure of organization's relations. Therefore, the progressing necessity - continuously - in the convergence care between aesthetics and ethical aspects by any organization in order to develop a leadership that integrate us harmonically.

Key words: Coherence, aesthetic, ethics, organizations, leadership, corporative culture.

Profesor titular de Filosofía de la Universidad Rey Juan Carlos de Madrid. Académico de la Real academia de jurisprudencia y legislación española. Doctor en Filosofía y en Derecho por la UCM, Diplomado en Ética por La Sorbona de París. Secretario del Capítulo de Estética de AEDOS. 


\section{Introducción: interés del tema de nuestra investigación}

Desde largo tiempo atrás, se cuenta con reflexiones de gran profundidad acerca del valor del Arte y de lo estético para la existencia humana y la sociedad, según revelan los textos de autores tan conocidos como Platón (1990) o Heidegger (1958). Sin embargo, todavía hoy no existen suficientes investigaciones, estudios, métodos de aplicación práctica o programas de formación que examinen este asunto en el terreno concreto de las organizaciones o instituciones humanas y exploren su fecundidad. Tampoco resultan frecuentes los análisis en los que se desarrolle adecuadamente la consideración de la realidad estética en sintonía con la de la ética en las corporaciones y grupos.

Son pocos, igualmente, quienes se han adentrado en la meditación de esta precisa cuestión de manera específica en las empresas. En español, por ejemplo, pueden citarse las fecundas aunque puntuales contribuciones en este último terreno de Sánchez (1991), Alvira (1997) o Fernández (1997). En este estudio se analizan estas cuestiones en relación con las organizaciones en general, de manera que la reflexión resulta aplicable a las diversas clases de las mismas. De este modo, aunque se considera el ámbito de lo corporativo o empresarial, no se escinde o aísla aquí para su análisis separado. Por ello, desde el inicio, se previene que cabe establecer diferencias para el propósito de la investigación presentada de acuerdo con la tipología organizativa, asunto que probablemente pueda merecer ulteriores investigaciones.

A causa de lo anterior, este tema de investigación no resulta exento de originalidad, como tampoco el hecho de llamar la atención, advertir con más intensidad de lo habitual, acerca de la importancia de la dimensión estética de las organizaciones humanas, y el demandar la conexión necesaria de este aspecto con la ética y la coherencia integral de las organizaciones. Se va a buscar aquí, asimismo, finalmente, el proporcionar algunas claves de posible aplicación práctica para el contexto de las corporaciones. 
Dentro del ámbito acotado, de acuerdo con lo precedente, una tarea de especial relevancia consiste en el estudio y la indagación acerca de la necesidad de coherencia entre lo estético y lo ético en las organizaciones vinculadas con el trabajo, así como en todo tipo de instituciones. Esta cuestión posee un valor de particular significación para aquellos que están comprometidos con la excelencia y calidad total en las organizaciones humanas. Hoy, este asunto resulta innovador en el ámbito del desarrollo organizativo, empresarial y directivo; pero, en su día, también lo fueron la estrategia, el marketing o los RRHH. Sin duda, la estética organizativa y su coordinación con la ética pueden dar frutos muy interesantes. Piénsese, por ejemplo, en clave de la mejora continua e innovación permanente, por parte de las instituciones contemporáneas.

\section{Ética y estética de la organización}

Contraponer la ética ${ }^{1}$ la estética organizativa, afirmar que lo estético contradice por definición o por naturaleza a lo ético, constituye una grave equivocación de partida. Este error, no infrecuente en nuestro tiempo, posee dañinas consecuencias "prácticas" para cualquier organización. Ello responde, sin duda, a una errónea visión de lo ético y de lo estético, así como de la relación que existe entre ambos. Sin embargo, cabe encontrar hoy reflexiones que enseñan a unir e integrar de modo articulado los campos de lo estético y lo ético de una forma clara, honda y fecunda, como muestran las investigaciones contemporáneas a este respecto de pensadores como López (1987) y Blanco (2001). En cualquier caso, las personas y organizaciones tienen que cuidar siempre ambas esferas, la ética y la estética, y además procurar la coherencia entre sí de las mismas. Como la forma y el fondo, el continente y el contenido, todo sujeto y grupo incluyen siempre ambas dimensiones, y deben esforzarse permanentemente en alcanzar la mejor sintonía entre ellas.

1 Acerca de la ética organizativa y empresarial, remitimos a la contribución de Bajo y Fernández (2009) y a Fontrodona, Guillén y Rodríguez (1998). 
Lo ético constituye una dimensión de la vida y actuación humanas, vinculada fundamentalmente con la atención a valores ligados a la responsabilidad, como la justicia y el respeto (Méndez, 1995). Ahora bien, una primera reflexión en torno a esta labor puede indicarnos que esta incluye el cuidar las formas. En efecto: formas vacías o privadas de significados auténticos y de valores verdaderos, acaban por traicionar a la persona y a la institución que las presentan. El motivo se encuentra en que dichas formas vacías o huecas se convierten en un puro espejismo que termina por decepcionar a quienes se acercan a él, un artificio sin sentido, un reclamo sin substancia o valor real, una mera y frustrante apariencia que defrauda al cabo a los que se relacionan con ella.

El extremo peor, en esto, estriba en la actitud hipócrita o farisea, que convierte la estética exclusivamente en un puro maquillaje. En tales casos, este "disfraz" se realiza no ya para atraer, agradar o manifestar algo a alguien, sino para engañar y manipular, haciendo creer lo contrario de lo real. La estética se utiliza, en estas circunstancias, de una manera contrapuesta a la ética. Conviene, pues, que las organizaciones integren adecuadamente sendas dimensiones.

\section{Estética, cultura e identidad organizativas}

Lo estético o formal constituye siempre parte de la cultura, tanto personal como organizativa. Junto a ella se hallan la ética, la política, la técnica, la economía... En efecto, las organizaciones poseen una cultura, un trasfondo de presunciones y creencias compartidas, y esta juega en su visión un relevante papel, tal como indicó ya Schein (1988). Esta cultura conforma su identidad, su personalidad, su carácter distintivo, lo que las diferencia de otras. Y, además, envuelve e integra a una gran variedad de elementos característicos, de acuerdo con el hondo análisis acerca de esta multifacética realidad desarrollado por Gómez (1999). Ahora bien, en esa identidad organizativa se encuentra también lo estético. La estética de una organización, a la vez, integra y proyecta o manifiesta la identidad, el ser de esa organización. De este modo, las instituciones muestran su ser a otros, y así se relacionan o 
comunican consigo mismas (con sus integrantes o miembros), y con todo lo que las rodea.

Cabe acudir a la historia en busca de señalados ejemplos de lo precedente. Así, mucho se ha dicho acerca de la diversidad estética entre las diferentes casas reales, imperios y sistemas de poder. Es sabido que la peculiar estética de los primeros austrias revela su carácter austero y solemne o serio. Ello se aprecia notablemente al contemplarla en relación con la de los borbones, de personalidad mucho más opulenta y abierta a lo banal. Este hecho lo ejemplifican los palacios, de estilo herreriano, como El Escorial, frente al barroco rococó de Versalles o los de La Granja, Aranjuez, de Oriente, etc. (cf., acerca de esto, los estudios sobre la evolución del barroco de Wölfflin y otros historiadores del Arte).

La cultura organizativa incluye metas, principios, valores, normas, procedimientos o métodos, realizaciones, lenguajes o formas de comunicación. Desde luego, todo ello posee una dimensión ética. Ahora bien, asimismo existe un aspecto estético de tales elementos de las organizaciones. La congruencia en todo ello proporciona unidad a los grupos. Mas, también, conviene advertir que debe darse un equilibrio entre la coherencia reclamada entre el lado ético y estético de estos elementos, y la consistencia o unidad estética de todos los integrantes de la organización y la característica y vital libertad de la estética organizacional (por ejemplo, caben semejanzas estéticas en la organización, pero también legítimas diferencias, etc.). De hecho, la llamada "unidad en la diversidad" constituye la categoría básica o angular de lo estético. Desde luego, resulta fecundo el que exista cierta sintonía o armonía entre los valores éticos, políticos, técnicos, económicos y estéticos de la organización. De otro modo, la identidad se quiebra o fractura, y el grupo no se reconoce como es ni se vincula adecuadamente con los otros.

Como ejemplo de esa coherencia, puede mencionarse la famosa estética faraónica. Esta resulta muy singular u original y destaca lo ajustado, lo perfectamente sincronizado o integrado, de sus múltiples 
componentes al sentido global de lo que encarnó esta civilización. Sus tumbas, pirámides, sus templos, sus objetos y pinturas, sus estelas y jeroglíficos, se ligan entre sí en su peculiar estilo común. Todos ellos hablan al unísono, con una sola voz, de su particular concepción de la vida, estrechamente ligada a la muerte, y de su visión del estrecho vínculo existente entre el poder y la energía o el trabajo.

\section{La diversidad estética entre las organizaciones}

No existen dos organizaciones absolutamente idénticas, desde la perspectiva de su estética. Cada cual posee su identidad y, a la vez, su camino o estilo propios a la hora de manifestarla. Sí cabe, empero, establecer vínculos entre las estéticas de diversas organizaciones.

La diversidad estética de las organizaciones obedece a numerosos factores o motivos y, además, afecta a todos sus elementos formales. Entre otras causas, esta diversidad estética de las organizaciones responde a su propio origen o principio -al ser de sus fundadores(causa agente), y a sus fines o propósitos (causa final). Cuando se analiza la estética de los bancos y entidades financieras, por ejemplo, se constata que busca expresar lo duradero, lo sólido, lo estable, a fin de transmitir confianza, seguridad, fiabilidad. Sin embargo, la estética de las organizaciones relacionadas con lo selecto o privilegiado (como clubs, asociaciones de poder e influencia, industrias de productos caros o exquisitos), en cambio, aspira a comunicar delicadeza, refinamiento, sutileza, detalle, pormenor.

\section{Lo estético contribuye a alcanzar los fines de la organi- zación}

La dimensión estética de una organización afecta a cuanto esta realiza, tanto interna como externamente. En cierto sentido, nada queda del todo exento de la influencia de este aspecto formal. Ahora bien, esta dimensión estética de las organizaciones les ayuda a vivir y desarrollar determinados valores, en particular los más ligados a lo formal, como la belleza, la expresividad, la originalidad o la creatividad. 
En el tiempo presente, la era de la globalización, las organizaciones y sus miembros no pueden descuidar o desatender ninguno de los elementos que concurren o colaboran a su esfuerzo común por alcanzar sus metas. Lo estético ha prestado, en este sentido, un servicio indispensable, en todo tipo de instituciones, desde muy antiguo, y debe seguir haciéndolo, hoy más si cabe, cuando el contexto resulta de una enorme competitividad y las interrelaciones organizativas son particularmente intensas.

Además, es esta una época atraída fuertemente por los valores estéticos, y las organizaciones que deseen estar a la altura de sus retos contemporáneos no deben desdeñar un esmerado cultivo de su propia dimensión estética. Para ello resulta indispensable la formación continua de sus directivos, también en este hermoso campo, pues solo con un esmerado liderazgo en este terreno cabe esperar el progreso de su excelencia o calidad integrales.

En estenuevo panorama, el desarrollo estético detodos losintegrantes de una organización se convierte en un factor de competencia y ventaja crucial. Un factor que impregna, además, todas las acciones acometidas por la institución. Representa su rostro, la encarnación formal de su propia cultura corporativa y de su estilo de liderazgo y de relación con otros. La formación estética se convierte, así, en una de las claves más importantes del clima organizacional y de la motivación, parte esencial de la filosofía corporativa, del hacer y convivir de sus colaboradores.

Lo estético aporta su fecundidad a un variadísimo conjunto de campos, relacionados con la organización. Entre otros, muy especialmente, ha de señalarse el que puede fomentar la cooperación. Ello, dado que ayuda a integrar los esfuerzos de acuerdo con un valor estético decisivo como es la armonía, el equilibrio y la proporción ordenados a la unidad, realidades hondamente vinculadas con la belleza. En efecto, el trabajo en equipo se ve iluminado gracias a estos aspectos, pues lo estético inspira la coordinación armoniosa de los esfuerzos, su mejor integración y, así, colabora al éxito de la organización. 
Dado su gran número, cabe seleccionar, aquí, de modo sucinto, una serie de beneficios que derivan, para las organizaciones humanas, del atender o cuidar su aspecto estético. Entre ellos cabría mencionar los que siguen:

- El desarrollo de la atención hacia lo estético, en las relaciones con clientes, proveedores, socios, colaboradores, redunda en una ventaja competitiva por el incremento del valor total de la organización.

- Diferenciación: ayuda a madurar una identidad corporativa más marcada y apreciable, que permite distinguir a unas organizaciones de otras.

- Fomenta el cuidado de las formas y figuras, de la atención al detalle. Aumenta así la "calidad" en el quehacer corporativo cotidiano.

- Mejora el ambiente de trabajo, las relaciones y el logro de una cooperación más armónica. Genera un clima interno dotado de mayor unidad y compenetración, que favorece la motivación, el esfuerzo y la coordinación.

- Impulsa la innovación y la investigación de nuevas posibilidades, a través del incremento de la creatividad, tanto personal como grupal.

- Promueve las capacidades reflexivas individuales y en grupo, además del diálogo conjunto en el equipo u organización.

\section{El aspecto estético del liderazgo}

En toda organización se da una u otra forma de liderazgo, una orientación clave y personal que debe ponerse al servicio del bien común ${ }^{2}$. A su vez, toda dirección, liderazgo y desarrollo organizativos comportan una dimensión de relación humana, la cual se ve integrada por múltiples elementos, entre los cuales juega un relevante papel el equilibrio entre lo intelectual y lo afectivo en las personas, entre las ideas y las emociones, tal como ha mostrado De Sendagorta (2004).

2 Acerca del liderazgo remitimos a Querol (2013). 
En profunda conexión con ese peculiar eje que integra lo afectivointelecual, se encuentra precisamente el lado estético del liderazgo y de la organización, del que ahora se ocupan estas líneas. A este propósito, debe constatarse que cada líder y cada estilo peculiar de liderazgo organizativo poseen una estética propia, característica.

Gracias a su estética distintiva, el líder puede manifestar una amplia serie de valores, de muy diferente clase. Orienta también, con su estética definida, hacia los fines comunitarios; coordina, comunica y motiva con ella a su grupo. Incrementa, por medio de ella, la unidad y cohesión de su comunidad, refuerza o potencia la identidad de su institución y pone o mantiene a esta en movimiento.

Sobre este íntimo vínculo, entre el estilo de liderazgo y lo estético, existe un testimonio muy interesante en las conocidas reflexiones del arquitecto y escenógrafo de Hitler, Albert Speer (así como en los documentales y análisis de sus desfiles, mítines o reuniones). Estas grandilocuentes, premeditadas y exhibicionistas puestas en escena de la estética hitleriana, se explican por la intencionalidad y propósito de mentalización colectiva y de movilización de masas que tales esfuerzos pretendían suscitar en el pueblo alemán, y aún más allá de este. Pero, ante todo, responden a la característica personalidad egológica de aquel que las protagonizaba. En el fondo, revelan el carácter envolvente o aglutinador de voluntades en torno a sí de su idolátrico protagonista, y el efecto de rendida sumisión que buscaba despertar Hitler en torno a su propia figura como conductor o guía de masas fervorosas y entregadas.

\section{Influencia del líder en la estética}

El estilo o estética del líder impregna toda su labor. Además, de algún modo, dicho estilo singular condiciona el entorno o ambiente global, la cultura organizacional, el clima o el ámbito en el que respiran los diferentes sujetos ligados a la institución. Este estilo lo envuelve todo, se filtra en la atmósfera del colectivo y afecta a los menores detalles y rasgos, vía imitación o emulación y reproducción. Influye en los valores 
estéticos del grupo o en el conjunto de lo estético de la comunidad, de una manera especialmente relevante. Ello, porque en el fondo proviene de su principio directivo. El líder es quien más puede influir en lo estético, ya sea de forma directa o indirecta, incluso por omisión (como cuando consiente una diversidad radical, o si desatiende por completo tal aspecto).

Así, la personalidad del líder, sus propios valores y actitudes, se traslucen en su estética. De ahí el que debamos hablar también de la estética de su liderazgo, conocerla y criticarla. A este respecto, una aguda interpretación de la estética en el liderazgo, en clave de crítica a través del humor, se halla en la conocida película El gran dictador, de Chaplin. Sus escenas enseñan cómo la personalidad singular del jefe se proyecta sobre lo que le rodea, contagiándolo todo con su acento, y ello también, notablemente, a través de la estética.

\section{Consideraciones prácticas para el desarrollo aplicado de la estética organizativa, en clave de coherencia:}

\section{1) Procurar la expresión de lo esencial}

Según todo lo precedente, las organizaciones han de asumir el que, para ellas, resulta vital el cuidar especialmente la expresión estética de sus valores corporativos centrales y reales (identitarios). Ahora bien, esto constituye una labor y, a la vez, un arte, por descontado siempre mejorables.

Expresar de modo adecuado en lo formal quién se es, en cuanto comunidad, favorece las relaciones a largo plazo, haciéndolas más claras y auténticas. Se evitan así incomprensiones, confusiones, equívocos y decepciones graves ulteriores. Han de elegirse y afinarse aquellas formas externas que mejor transmiten el núcleo de nuestra identidad y cultura corporativas.

Ejemplos de ello cabe encontrar de muy diverso tipo. Así, resulta lógico que una empresa consagrada a las nuevas tecnologías de la 
información pretenda reflejar sus valores de comunicación y dinamismo a través de una decoración basada en la transparencia, la apertura de espacios y la interrelación de ambientes.

En contraste con lo anterior, una empresa multinacional que desea transmitir valores de solvencia, pujanza, fuerza o solidez, puede comunicarlos radicándose en edificios grandiosos, rascacielos de impresionante porte y altura, de interiores solemnes, amplios y modernos. En cambio, una pyme dedicada a la formación continua, que quiera expresar el valor del progreso continuo y la innovación, parece comprensible que elija para su sede central una construcción modernista, de corte ultra contemporáneo, con interiores funcionales, que permita combinaciones flexibles y cambiantes de sus diversos elementos expresivos.

\section{2) Fraguar un estilo propio}

Las organizaciones que pretenden la excelencia no pueden ahorrarse el esfuerzo de buscar y ahondar en cierta "unidad" estética o un estilo propio. Este estilo agrupa y proporciona un sentido de coherencia y unión a los diversos elementos formales, incrementando exponencial e integradoramente el valor de todos ellos.

Lograr tener "estilo", unas formas propias y originales, ayuda a diferenciarse y, así, refuerza la identidad y su comunicación. Pero esto no debe ir en detrimento de la legítima diversidad formal. Debe conjugarse la unidad en la diversidad, el cambio y la permanencia, el orden y la libertad formales. A este propósito, cabe recordar la obra cinematográfica Tiempos modernos, en la que Chaplin refleja con ironía el exceso de uniformidad industrial, y ello también en cuanto a lo estético o la manifestación de las formas sensibles.

Frente a esta extremada uniformidad, puede citarse la estética característica o singular desarrollada por unos u otros imperios, casas reales o grupos influyentes, así como la de determinadas organizaciones internacionales y la de las corporaciones más destacadas, que con 
frecuencia adoptan un estilo propio y distinto, que resulta diferente y característico. Sin embargo, esto no debe implicar el caer en su seno o interior en los abusos de una total homogeneización estética, o en uniformidades excesivas que ahoguen la riqueza de la diversidad interna.

\section{3) Fomentar líderes que desarrollen una estética corporativa co- herente}

Si los líderes resultan decisivos, también en lo estético, las instituciones deben desarrollar líderes que promuevan eficazmente su estilo compartido. Estos tienen que lograrlo sin caer en rigideces, sino desde su personalidad propia y desde su encuentro con las personalidades de sus colaboradores.

El liderazgo también ha de fomentar los valores estéticos, y no solo ya a título individual, sino, a su vez, con respecto al grupo o equipo en cuanto comunidad, y hacerlo siempre de acuerdo con un progreso continuo. Para ello, el líder ha de imbuirse de tales valores o estilo estético y formar a otros desde su propia y singular interpretación de los mismos. Como ejemplo, recordemos el relevante papel de mecenazgo e inspiración jugados por numerosos líderes organizativos, a lo largo de todas las épocas, desde reyes a ricos potentados económicos, pasando por las grandes figuras religiosas de todos los tiempos, como el papado y su notable labor en la Historia del Arte.

\section{4) Promover lo formal sin defraudar}

Sin duda, cabe legítimamente suavizar o atemperar las propias debilidades en cuanto a valores organizativos a través de la estética, con tal de que no se caiga en el "confundir" sobre ello. Todos pueden velar, en cierto grado, imperfecciones; mas no mentir sobre ellas. El arte de las formas aconseja velar en cierto grado algunos defectos o debilidades, también como grupo, con respecto a lo externo. No todo ha de reflejarse sin más tal cual es cuando la prudencia demanda discreción o cautela. Pero ello no debe conducir nunca a la mentira, ni 
a su extremo: la hipocresía. Estas serán contraproducentes, sin duda, para todos, a nivel interno y externo.

Los ejemplos sobre esto se hallan en la vida cotidiana misma. Así, un hombre bajo podría disimular su estatura con alguna calza, mas caería en la exageración ridícula si sus calzas lo elevan de un modo desproporcionado. De igual modo, las organizaciones pueden modelar estéticamente sus propias insuficiencias, mas no manipular con respecto a ellas, llamando de manera injusta al error.

\section{Conclusiones para la aplicación práctica en las organiza- ciones}

La estética organizativa, tal como se ha mostrado, tiene que ver con las formas -en cuanto exteriorizadas, perceptibles, sensibles-, con el cuidado de dichas formas y con la necesidad de reflexionar sobre ellas con profundidad en relación con las organizaciones. Ahora bien, lo cierto es que todos hoy parecen darse cuenta de que cuidar las formas resulta importante y bueno para los individuos, y así se valora mucho socialmente la estética, a veces casi en exclusiva. En las organizaciones humanas, no solo ya en los individuos, las formas externas también importan de un especial modo y pueden influir enormemente en su eficacia y sus resultados. La causa reside en que las organizaciones tienen que ver con personas, y las personas poseen sensibilidad hacia las formas, pues estas les afectan, conscientemente o no.

Sin embargo, todavía hoy no existen apenas investigaciones, estudios, métodos de aplicación práctica, programas de formación o desarrollo, en o para las organizaciones, que desarrollen adecuadamente su realidad estética. Así, constituye una necesidad el hecho de llamar la atención sobre este aspecto específico y demandar la conexión del mismo con la ética corporativa, a la par que se reclama una coherencia integral en las organizaciones.

De acuerdo con la presente investigación, resulta conveniente desarrollar mucho más la sensibilidad formal en las organizaciones, 
incluso en las empresas, y realizarlo exige promoverla en los directivos o líderes, y, en general, en todos los miembros de las diferentes instituciones. Esta consideración final puede juzgarse una clave útil o de alcance práctico, pero, ante todo, supone una invitación directa a contemplar y estudiar con más atención o cuidado este fecundo campo, en el que tanto queda por investigar y emprender. Existe la necesidad de impulsar la iniciativa en este terreno, y hoy parece innovador en el ámbito del desarrollo organizativo, empresarial y directivo. Sin duda, la estética organizativa puede dar frutos muy interesantes para las corporaciones y la sociedad, en especial si se atiende a las claves de "la calidad total" y la mejora continua.

A todo lo anterior ha de sumarse la idea que consiste en advertir que "la estética organizativa no debe ir separada de la ética". De otro modo, se convierte en pura apariencia para mover, pero vacía de contenido, orientación y verdad o realidad. Así, la estética y la ética de una organización deben resultar coherentes entre sí y con la propia cultura corporativa. De la ética organizativa, sin embargo, se habla muchísimo, y casi todos los programas de desarrollo directivo la incluyen. En cambio, la estética aparece en dichos programas raramente, cual una cuestión relegada o incluso excéntrica se diría. Mas, al cabo, la ética y la estética se necesitan mutuamente y su unidad resulta fundamental.

Por otro lado, en este terreno no basta la especulación teorética. Se tendrían que realizar reflexiones fecundas sobre esto, y además ayudar a aplicarlo en la vida organizativa concreta. Por eso, se propone aquí el que se lleven a cabo experiencias y actividades "prácticas" de estética organizativa, directiva y empresarial en conexión con la ética e identidad corporativas. Estas actividades prácticas -de muy diversa clase- las debe realizar ante todo cada directivo o emprendedor y cada equipo de trabajo concreto, cada empresa o institución determinada. Incluso cabe aventurar que convendría contar con cierta "asesoría" de estética organizativa adecuada. Esto no equivale a un simple estudio de la decoración, sino que demanda un análisis de todas las formas 
sensibles que existen en la vida de una organización o empresa, de su efecto, de su sentido, de su mejora y de su "coherencia" con la cultura y la ética institucional.

Sin duda, el principio fundamental para una fecunda aplicación de la estética a la organización radica en saber armonizar las formas sensibles con la identidad, con el propio ser y la cultura organizativa. Las formas de hacer y de actuar hablan de la propia identidad, del ser organizativo concreto, y esta misión tienen que realizarla de un modo coherente e integrador.

Así, de modo sintético, para concluir estas consideraciones, cabe subrayar algunas ideas clave de evidente incidencia práctica. Entre ellas, tan solo se citan las que siguen:

\begin{abstract}
1/ La estética se capta o percibe, e influye así en el conjunto o todo de la vida y ambiente corporativos.

2/ Siempre se puede progresar en ella, y en su sintonía o coherencia con los restantes elementos corporativos.

3/ Lo estético se vincula, en especial, con las personas, pues son ellas quienes la desarrollan y promueven. Así, aunque alcanza a la presentación de las cosas, afecta también a las formas de comportarse de los sujetos. Ello conlleva una clara vinculación con la ética.

4/ No solo no debe desdeñarse, sino incluso hay que captar y cultivar en la práctica su enorme influencia, en un sentido positivo, siempre coherente con el ser y la identidad institucionales. Esta dimensión de lo estético ha de desarrollarse como un fiel y leal reflejo o proyección verdaderos, fiables y ante todo consistentes con la ética y los valores de toda la organización.
\end{abstract}

En conclusión, resulta necesario un mayor desarrollo de la sensibilidad formal en las organizaciones, incluidas aquí las empresas y, desde luego, en los directivos y, en general, en todos los profesionales o miembros de las instituciones de ámbito laboral. Esto siempre en una honda armonía con lo ético o los valores de la responsabilidad. He aquí, por tanto, una invitación directa a considerar con más atención y cuidado este fecundo campo, en el que tanto queda por investigar y por poner en práctica. 


\section{Referencias bibliográficas}

Alvira, R. (1997). Dimensiones estéticas de la empresa. Cuadernos Empresa y Humanismo, $67,2-13$.

Bajo, A. \& Fernández, J. L. (2009). La responsabilidad social y la ética empresarial en un paradigma de empresa sostenible. Madrid: Editorial Universidad Pontificia Comillas.

Blanco, P. (2001). Estética de bolsillo. Madrid: Ediciones Palabra.

De Sendagorta, E. (2004). El afecto a la empresa. Madrid: Ediciones Internacionales Universitarias.

Fernández, A. (1997). La empresa como realidad estética. Cuadernos Empresa y Humanismo, 68, 3-37.

Fontrodona, J, Guillén, M. \& Rodríguez, A. (1998). La ética que necesita la empresa. Madrid: Unión Editorial.

Gómez, R. (1999). La cultura de la empresa. Madrid: Unión Editorial.

Guillén, M. (2006). Ética en las organizaciones: construyendo confianza. Madrid: Ed. Pearson.

Heidegger, M. (1958). Arte y poesía. México D.F.: Fondo de Cultura Económica.

López, A. (1987). Estética de la creatividad. Barcelona: PPU.

Méndez, J. M. (1995). Introducción a la axiología, tomos I y II. Madrid: Estudios de Axiología.

Platón (1990). Hipias mayor, trad. M. Araujo et. al. En Obras completas. Madrid: Aguilar.

Querol, F. (Coord.). (2013). Liderazgo: hoja de ruta. Zaragoza: Ediciones Universidad San Jorge.

Sánchez, J.A. (1991). Discurso: La empresa como realidad estética. Madrid: Real Academia de Bellas Artes de San Fernando.

Schein, E.H. (1988). La cultura empresarial y el liderazgo. Barcelona: Plaza y Janés.

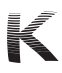

